"Examining the quantity and quality of online sustainability disclosure within the Jordanian industrial sector: a test of GRI guidelines"

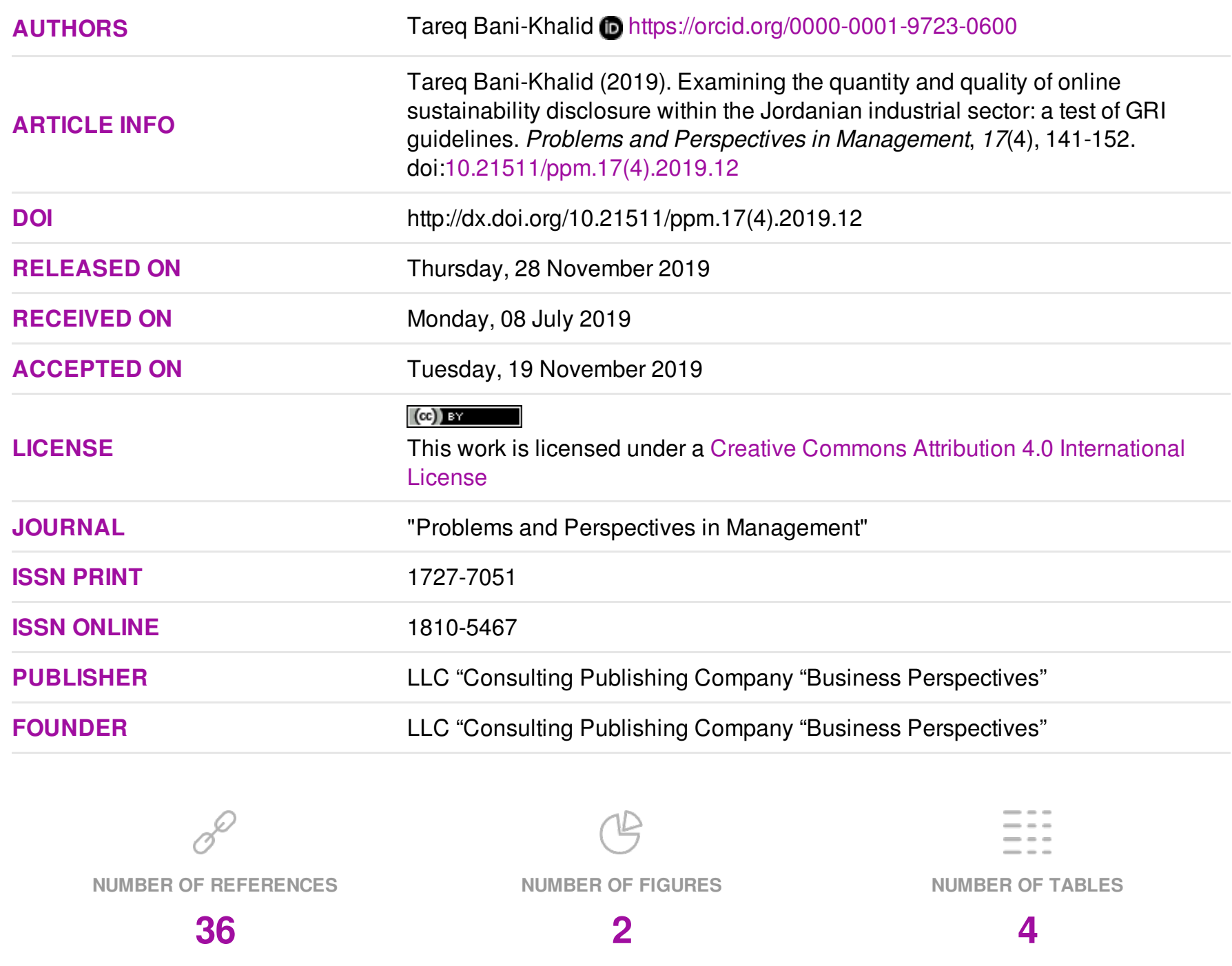

(C) The author(s) 2023. This publication is an open access article. 


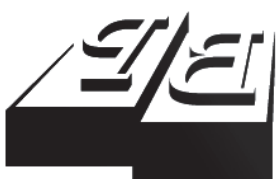

BUSINESS PERSPECTIVES

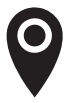

LLC "CPC "Business Perspectives" Hryhorii Skovoroda lane, 10, Sumy, 40022, Ukraine

www.businessperspectives.org

Received on: $8^{\text {th }}$ of July, 2019 Accepted on: $19^{\text {th }}$ of November, 2019

(C) Tareq Bani-Khalid, 2019

Tareq Bani-Khalid, Ph.D. in Financial Accounting, Assistant Professor, Accounting Department, Faculty of Economics and Administrative Science, Al al-Bayt University, Mafraq, Jordan.

\section{EXAMINING THE QUANTITY AND QUALITY OF ONLINE SUSTAINABILITY DISCLOSURE WITHIN THE JORDANIAN INDUSTRIAL SECTOR: A TEST OF GRI GUIDELINES}

\begin{abstract}
Reporting on corporate sustainability practices as being in congruence with social expectations is the core idea of legitimacy theory. Therefore, nowadays many organizations are making efforts to inform their stakeholders about the social, environmental and economic changes in their performance. Consistent with the argument above, this paper aims to examine the quantity and quality of corporate online sustainability in formation of the industrial sector in Jordan based on the Global Reporting Initiative guidelines. In line with content analysis method, this paper analyzes the quantitative sustainability indicators disclosed during last 7 years $(2012-2018)$ by all the industrial sub-sectors listed on the website of Amman Stock Exchange. The results revealed that although all Jordanian industrial sub-sectors practice of the quantitative sustainability disclosure is in a modest degree in the period of 2012-2018, the emphasis on environmental and economic indicators was less than on social indicators in the corporate online reports. Results on qualitative analysis indicated that, considering all sustainability indicators, only the disclosure on indirect economic impacts, procurement practices, product responsibility, and economic performance have been reported at satisfactory levels of quality but with no compliance of GRI guidelines. According to the obtained results, policy makers in the Jordanian industrial sector should be very important players in order to open the channels of dialogue with corporate managers on the importance of their role in taking more responsibility for their non-financial operations. Consequently, this should ensure more transparent accountability through more quantitative and qualitative sustainability disclosure in the corporate reports.
\end{abstract}

Keywords

quantity, quality, Corporate Sustainability Disclosure (CSD), Global Reporting Initiative (GRI), Amman Stock Exchange (ASE), Jordan

JEL Classification M41, M48

\section{INTRODUCTION}

Hahn and Kuhnen (2013) write that: "the growth of sustainability reporting in the new millennium seems to have invigorated the entire field of research" (p. 11).

Consistent with the quotation above, the second millennium is regarded as the new golden age of transparency and the expansion of Corporate Sustainability Disclosure (CSD) literature. Indeed, this decade saw the expansion of public awareness about the importance of sustainability information in encouraging further recognition of the other stakeholder demands; thus, legitimating corporate business practices. Given that companies recognize their accountability to a broad group of stakeholders, therefore, they would need to make further efforts to inform the stakeholders about their non-financial strategies by using any form of communication. In its broadest sense, 
corporate reports are the most common source used to meet the stakeholders' expectation regarding the sustainability practices. However, it is also argued that corporate reporting through their annual reports or through separate reports is the traditional function, and meets the limited needs of stakeholders. Thus, many corporate businesses today pay attention to the internet as valuable and available means that can be easily accessed by different stakeholder groups.

More recently, with the breadth of internet technology, many organizations have realized the importance of utilizing their websites as an important way to show themselves as accountable parties within their communities. As such, corporate sustainability initiatives have gradually begun to appear on their websites as a quick means helping them to expand their communication with unlimited number of potential and existing stakeholders.

CSD, in the period of 2000s, was also marked by international recognition, especially in developed countries. For example, the Global Reporting Initiative (GRI) was established in 2002 as the world's largest guidelines for reporting on the economic, environmental and social dimensions of business activities. Indeed, the paths of sustainable practices have become substantially clearer in the recent years. Corporate sustainability practices in most Western countries have witnessed a remarkable transformation in the way to sustainability in the expectations of an organization's sustainability performance and its disclosure strategy. Consequently, corporate businesses believe that maintaining a good and cohesive relationship with all stakeholders through voluntary initiatives is no longer the only precondition for legitimizing their existence, where creating a long-term relations by offering a variety of information that reflects their sustainability performance also leads to legitimizing their actions. As such, corporate sustainability has evolved from the focus on promoting corporate environmental, social, and governance performance to more sustainability initiatives disclosure that can drive high quality financial performance. In fact, CSD, as a global trend, has become an increasingly useful way of creating long-term business value, and win stakeholder trust. Therefore, several European Union countries are making CSD obligatory. These includes the UK, Sweden, Denmark, France, and Germany.

On the other hand, CSD practices in most emerging and less developed countries are documented as an early stage. Similarly, corporate businesses in the Arab world, particularly in Jordan, still have a lack of CSD studies and its role in long-term goals of a firm. In this regard, Abu-Baker and Nasser (2000) argue that: "...while other studies have previously examined the extent of corporate Non-financial disclosure practices in a number of developed and developing countries, they failed to survey Arab countries" (p. 19).

In a developing Arab country like Jordan, corporate managers have a lack of awareness about the sustainability reporting role in avoiding potential conflicts with other stakeholders. Indeed, this lack of awareness was the most important barrier front of CSD research during the last years in Jordan. This leads to reducing different stakeholders' trust in the credibility of corporate reports, putting, thus, their reputation at risk in such case.

Over the recent years, the Jordanian government realized the sensitivity of the relationship among stakeholders, specifically after the emergence of a number of court cases against corporate moral responsibility in the Jordanian business environment. In 2016, the ASE has issued a report on "Jordanian Corporate Sustainability" (JCS) as a first step towards the definition of sustainable corporate development, and its benefits to all stakeholders. Specifically, the JCS report states that all companies listed on ASE expect the companies to commit themselves to the general guidelines in disclosing their economic and socio-environmental impacts (ASE, 2018).

In the early 2017, ASE has also joined the Sustainable Stock Exchange Initiatives, which was a vital step towards developing the CSD practices in Jordan. Farther, the ASE has also encouraged all companies to shift to use the internet and corporate websites in reporting their activities, which can help them to 
reduce the limitations of printed reports, such as, reporting costs and limited accessibility of such printed reports. Although the ASE's efforts towards raising all business' awareness about the importance of CSD were clear and successful in adopting such practices in the last three years, the practices of online sustainability reporting has not yet been the subject of empirical studies in Jordan. Proceeding from this problematics, the following two research questions are necessary to be raised here to achieve the main research objective, as presented in the next section.

Q1: What is the quantity and quality of online sustainability information by listed Jordanian companies based on adopted GRI guidelines?

Q2: What are the patterns of CSD that are useful to the Jordanian stakeholder based on adopted GRI indicators?

\section{RESEARCH OBJECTIVES}

In line with the above research questions, the main purpose of this paper is to explore the quantity and quality of sustainability information across sub-industries. The specific sub-objectives of the study are as follows: (i) to measure the quantity and quality of sustainability information by listed Jordanian industrial companies using the GRI index, (ii) to measure the compliance of the listed Jordanian industrial companies in reporting their sustainability information with the global guidelines like GRI.

In the fundamentals of any scientific approach, to achieve the above objectives of the research, the previous relevant literature must be reviewed first. Reviewing the literature in any research is a fundamental step that usually comes after determining the research problem and its objectives; given that the review of literature gives the researchers a great knowledge about the appropriate methodologies and methods for their research. The next section, therefore, highlights the literature review regarding CSD practices under legitimacy theoretical framework.

\section{LITERATURE REVIEW}

\subsection{Legitimacy theory}

Legitimacy theory is described by Tyler (2006) as: "...the characteristic of being legitimised by being placed within a framework through which something...is viewed as right and proper" (p. 376).

This characteristic is based on the idea of prescribing the behavior of companies as socially accept- able or not in evaluating their legitimacy. As such, corporate activities must be evaluated within the correct values and suitable beliefs of the societies (Suchman, 1995). It was argued that the legitimacy theory is one of the most useful insights for organization in making their actions more acceptable by different types of stakeholders (Deegan, 2007). Due to the importance of this characteristic, many scholars, like Guthrie and Parker (1989), Gray et al. (1995), used legitimacy theory within their studies as a more suitable basis to legitimize the corporate existence and their practices.

Indeed, the core idea of legitimacy theory lies in the concept of social contract between firms and their societies (Deegan, 2007). According to Guthrie and Parker (1989), this theory states that companies should operate within the norms of acceptable behavior in the social system. Thus, the continued survival and success of such a business will depend on how that business legitimizes its operations in the eyes of the public. Therefore, it could be argued that corporate bodies always seek to operate within the bounds of their respective societies and always strive to be perceived as being legitimate.

In essence, legitimacy theory is also based on the assumption that organizations need to comply with the social contract. In other words, this contract allows organizations to continue operations when, only, they are meeting their stakeholder expectations (Deegan, 2007). Thus, the greater the probability of an adverse variation in societal expectations of the way an organization acts, the greater the desire of this organization to change these adverse views to ensure their legiti- 
macy (Branco \& Rodrigues, 2006). Furthermore, Dowling and Pfeffer (1975) argue that organizations perceive that the change the adverse views to ensure the continuity of business operations within societal norms may require some remedial action. Corporate sustainability practices, as the most effective remedial actions, must be accompanied by public disclosure (Cormier \& Gordon, 2001).

The accounting literature has documented two primary approaches as strategic objectives of organizations for gaining the legitimacy. Making sure that the organization's activities are in congruence with societal expectations is the first approach. The second approach requires the organization to disclose on its activities and show that it is identical with these expectations (Gray et al., 1995). Accordingly, CSD can thus be seen as a corporate management strategy to clarify that activities and operations are moral responsible (Deegan \& Rankin, 1996), or to avoid being charged with a violation of the boundary that has been set by societal norms (Suchman, 1995).

Thus far, it is argued that legitimacy theory has been found useful by the literature in explaining the corporate sustainability behavior of organizations and their disclosure (Guthrie \& Parker, 1989).

Consistent with the arguments above, it could be concluded that "legitimacy theory is the most widely used to explain sustainability disclosures" (Campbell, Craven, \& Shrives, 2003, p.559). Having reviewed the legitimacy theory that was used in underpinning sustainability practices, the next section looks into some empirical evidence on sustainability disclosure.

\subsection{Prior studies}

Disclosure policy is the essential element in building the organizational legitimacy between corporate organizations and their societies (Suchman, 1995; Campbell et al., 2003; Deegan, 2007). Given this policy, these corporate communication channels, whether compulsory or optional, are one of the effective strategies in which corporates adopt certain practices such as disclosing their commitment in achieving the sustainable development to all stakeholders group. Thus, annual reports, supplementary reports, and brochures are the key channels for communicating the sustainability performance and impacts (GRI, 2013).

In fact, the rapid technological development in the information systems has also contributed a global communication ground for those interested in economic, environmental, and social changes in the business environment. Therefore, corporate sustainability practices have begun to appear gradually for the public through new ways of electronic communications (Morhardt, 2010).

Relevant literature review on CSD reveals that most published researches on the reporting of corporate sustainability practices were based on analyzing the corporate reports (Morhardt, 2010). Specifically, corporate printed annual reports have been widely used by researchers as a primary source in the data collection stage. Similarly, it was argued by Yaftian (2011) that corporate annual report is the most common form of corporate communication with stakeholders over the past three decades. That is why the company's annual reports still witness a widespread demand by researchers and investors as valuable sources in the majority of the existing studies on CSD practices (e.g., Gray et al., 1995; Deegan \& Rankin, 1996; Campbell et al., 2003; O'Dwyer et al., 2005; Huang \& Wang, 2010; Chiu \& Wang, 2015; Rezaee, 2017).

In contrast, little attention has been paid by the researchers to investigate the extent of sustainability information on the internet. These studies include Frost, Jones, Loftus, and Laan (2005) in Australian, Adams and Frost (2006) in Australia, Germany and the United Kingdom; Guthrie et al. (2008) in Australian, Branco and Rodrigues (2006) in Portugal, Morhardt (2010) in Global and Fortune 1500 companies, Herzig and Godemann (2010) in Germany, Dissanayake et al. (2016) in SriLanka, Sobhani, Amran, and Zauniddin (2012) in Bangladesh who have analyzed the information of CSD practices that was disclosed in the corporate reports.

Except for the studies of Dissanayake, Tilt, and Xydias-Lobo (2016) and Sobhani et al. (2012), all of the aforementioned studies have tended to have an exclusive focus on the analysis of corporate sustainability reports in several Western countries. For instance, in the international study, Morhardt 
(2010) used the Pacific Sustainability Index to analyze all information related to sustainability practices on the corporate websites of 25 international industrial sectors in Asia, Europe, and America. The results showed that the highest scores for all sectors were varying between $20 \%$ and $75 \%$. Specifically, the sectors of oil equipment, scientific, and photo equipment, wholesalers, and homebuilders have relatively low scores. This could be due to the most of these sectors not being in the Fortune Global 500 lists. Therefore, they are not concerned with sustainability issues and their reporting. Other sectors on Fortune lists like sectors of mail, food services, forest-paper products, and medical-products have higher scores of reporting.

Frost et al. (2005) used the GRI guidelines to examine the nature and extent of sustainability information that was reported on the websites of Australian companies. Although the overall levels of CSD were generally low, the results of the study also indicated that the Australian companies used their websites more than the discrete reports to report their sustainability. Similarly, Branco and Rodrigues (2006) examined whether Portuguese banks have used their websites as a medium to report the sustainability practices. Content analysis method has been used to classify the main patterns of such reported information and compare such information with similar information in banks' annual reports. The results showed that Portuguese banks use internet to report their sustainability practices on the official websites. It is found that Portuguese banks made more social disclosure than other sustainability patterns.

In the German context, Herzig and Godemann (2010) have examined the use of internet-supported CSD for German DAX30 companies in 2004, 2005, and 2007. The study used two research methods - content analysis and email survey - to examine the extent of the companies' use of internet in improving the disclosure practices, access, and comprehensibility of sustainability information. The results showed an overall increase in the use of internet by the German companies in reporting their sustainability practices on the websites from 2004 to 2007. Also, the results indicated that there was a shortfall in communicating the conflicts among environmental, social, and economic impacts of businesses.
Using the content analysis method, Huang and Wang (2010) analyzed the amounts of sustainability information for 116 companies for the period 2006-2008 in China. They found that disclosure on social and economic aspects were more focused in the corporate reports than the environmental aspect. Likewise and Kolk (2010) used the descriptive analysis method to investigate the level of sustainability information in 213 Fortune Global firms for the period 1999, 2002-2005. The results showed that reporting economic and social information showed the increasing trends over the period of the study (about 39\%, 52\%, and $69 \%$, respectively, in all the countries), while the environmental aspect has decreased in the total level of information between the firms. In Spain, Alcaraz-Quiles, Navarro-Galera, and OrtizRodriguez (2015) used the GRI index to analyze the level of online sustainability information for 55 municipal authorities. They found that social information was greater than the information on other aspects.

Using a mixed method, Ching, Gerab, and Toste (2013) examine the quantity and quality of economic, environmental, and social information disclosed by top 60 companies listed in Brazilian Stock Exchange in 2011. The results showed that $37 \%$ of sampled companies scored about $50 \%$ of quantitative sustainability disclosure. It is also found that Brazilian companies have the same unsatisfactory level of qualitative content when reporting their sustainability information. In addition, Maubane, Prinsloo, and Van Rooyen (2014) examined the extent and patterns of sustainability disclosure by sectors in the listed companies in Johannesburg Stock Exchange. The results showed that all listed sectors reported on the sustainability aspects with more focused on the socio-environmental aspects. Furthermore, the mining and materials sector reported more information on those aspects than the other sectors.

In a developing context, Dissanayake et al. (2016) analyzed the corporate annual reports, separate sustainability reports, and websites of 60 of the top 100 Sri-Lankan companies by using the content analysis method over the period 2011-2012. The study found that Sri-Lankan companies disclose more on their social practices than on environmental and any other voluntary practices. 
Commenting on the level of CSD practices between the developed and developing countries, Dissanayake et al. (2016, p. 1) argue that "While many studies have investigated CSD in developed countries, there is a dearth of research in developing countries. This is of particular concern, as the majority of the world's population lives in these countries, which experience their own social, political, and environmental issues." Therefore, there is an urgent need for CSD studies in such countries, particularly in the Arab world. To this end, this study looks at the quantity and quality of CSD in the Jordanian environment as a developing country.

Having had an insight into some literature on CSD, it is of significance to outline the research methods in the next section.

\section{RESEARCH METHODOLOGY}

This section looks into the specific methods and procedures to facilitate the conduct of this research on the Jordanian CSD. These includes (i) description of an appropriate research tools used in collecting and analyzing the data, (ii) it also provides a brief outline of the population and sources of CSD in Jordan. Therefore, the ensuing subsection discusses how content analysis is carried out in this study.

\subsection{GRI as a content analysis method}

In the past, empirical research has traditionally focused more on economic disclosure without any consideration of other sustainability aspects. However, focusing only on economic responsibilities without any consideration of other sustainability aspects has become the source of global concern that threatens the legitimacy of firms (Branco \& Rodrigues, 2006). Accordingly, the GRI emerged as an important disclosure indicator in satisfying the demands of broad legitimacy conferring stakeholders. It was also argued that GRI indicator is an important means that can be used to make sure that corporate social, environment, and economic activities were balanced. Thus, it helps in improving the quality of CSD to a higher level of transparency, credibility, and utility. Therefore, many corporate businesses recently pay more attention to disclosure on their sustainability practices by using such indicators (Rezaee, 2017).

"Thousands of companies have applied the GRI guidelines to their operations over the last decade. The guidelines support a standardized yet flexible approach to reporting and are designed as a consolidated framework for reporting performance against different codes and norms for sustainability" (GRI, 2013, p. 1).

In line with the above quotation, the GRI international indicator is an effective means for helping businesses to evaluate and report their impacts. It's also a great way to ensure that they behave in a socially, environmentally, and economically responsible manner to the benefit of current and future generations, and thereby contributing to the global economic sustainability (GRI, 2013). It is also documented that GRI, as a set of global guidelines, aims to develop and propagate globally appropriate and acceptable CSD guidelines for voluntary use by organizations reporting on wide issues of sustainability practices (GRI, 2015).

In fact, the GRI guidelines have clearly captured a variety of environment, social, and economic performance responsibilities. It also was acknowledged as the most widely used non-financial accounting disclosure guideline. However, the GRI guidelines are criticized for having different versions and numerous modifications (GRI, 2015). All versions were also launched in chronological order; thus all of these versions will not be appropriate for collecting and analyzing the data contained in the annual report.

Based on the above criticism, this paper will depend on the G4 indicators as a latest version, which was launched in 2013. Therefore, the period from 2013 to 2017 is the suitable time to investigate the amount of CSD in the annual reports. Another advantage for these period is that all corporate reports can be collected by using the official website of ASE.

Therefore, after determining the G4 index as a checklist model of collecting and analyzing the data, there is another important aspect to be taken into account. This aspect relates to the scoring the quantity and quality of disclosure data and its in- 
Table 1. Rating and scoring criteria of qualitative and quantitative information

Source: Abd-Mutalib et al. (2014), Anderson (2010).

\begin{tabular}{|c|c|c|c|c|c|c|}
\hline \multirow{3}{*}{ Quant } & Rating criteria & Score & $\mathbf{T}$ & Score by disclosure & \multicolumn{2}{|c|}{ Quan-score } \\
\hline & Non-disclosure & 0 & 0 & Non & \multicolumn{2}{|c|}{0 each word } \\
\hline & Disclosure & 1 & $\Sigma$ & Total words count & \multicolumn{2}{|c|}{1 each word } \\
\hline \multirow{4}{*}{ Quality } & Rating criteria & Score & $\mathbf{T}$ & Score by disclosure & Qual-score & Rating \\
\hline & Non-disclosure & 0 & \multirow{3}{*}{3} & \multirow{3}{*}{$\begin{array}{c}=(\text { largest-smallest value }) \backslash \text { number } \\
\quad \text { of values }=(2-0) / 3=0.67\end{array}$} & $0.00-0.67$ & Low \\
\hline & Disclosure & 1 & & & $0.68-1.33$ & Medium \\
\hline & Disclosure with full compliance & 2 & & & $1.34-2.00$ & High \\
\hline
\end{tabular}

dicators that can be used to obtain more relevant data. The next round after determining the collection method of information will follow a discussion of how to rate and score the quantitative and qualitative information as an application prelude to do this action in the next subsection.

\subsection{Rating and scoring}

In scoring the quantity and quality of sustainability information, two main types of scoring CSD are carried out in this study. These include: (i) weighted approach for scoring the quantity and quality of disclosures like Morhardt (2010), Lee (2015), (ii) unweighted approach for scoring the disclosure (Abd-Mutalib, Jamil, \& Hussin, 2014; Chiu \& Wang, 2015).

In accordance with Abd-Mutalib et al. (2014), this paper employs $0 / 1$ disclosure checklist as a quantity method to deal with all the wards as equal. As such, if a company disclosed any ward of quantity of sustainability information in its electronic annual report, it will be awarded one and if not, it will be awarded 0 . Also, in scoring the quality of sustainability information, a weighted measurement scale of 0-2 scores the corporate disclosures and its compliance with G4 guidelines on each disclosure indicator. Specifically, three types of scoring are assigned to discover the quality of sustainability disclosure. These include: 0 is a score for no information provided on sustainability indicators; 1 is assigned for general disclosures which do not meet the G4 guidelines; and 2 is for items disclosed in accordance with G4 guidelines.

Anderson's equation is used for the examination of disclosure quality. In fact, disclosure quality is obtained using the compliance quality score, which depends on the classification of GRI indicators into three types: low, medium, and high disclosure. This is obtained by dividing the combined score by 91 indicators by 7 years.

To get the average (0.67) is through combining largest value with the smallest value and then dividing them by the total of values $(0+2) / 3=0.67$. As such, scores from $0.00-0.67$ are rated as low; 0.68-1.33 as medium; $1.34-2.00$ as high disclosure compliance scores (Anderson, 2010).

\subsection{Population, sample, and data sources}

Indeed, the focus of this paper is to analyze the quality and quantity of CSD practices by Jordanian industrial listed companies in ASE. Thus, electronic reports represent the main source

Table 2. The study population

Source: ASE (2019).

\begin{tabular}{|c|c|c|c|c|}
\hline Sub-sector & No. of companies & Total & Sub-sector, \% & Total, \% \\
\hline Pharmaceutical and medical industries & 4 & \multirow{9}{*}{46} & 0.08 & \multirow{9}{*}{100} \\
\hline Chemical industries & 7 & & 0.15 & \\
\hline Cardboard and printing industries & 1 & & 0.02 & \\
\hline Food and beverages industries & 9 & & 0.19 & \\
\hline Tobacco and cigarettes industries & 2 & & 0.04 & \\
\hline Mining and extraction industries & 10 & & 0.21 & \\
\hline Engineering and construction industries & 7 & & 0.15 & \\
\hline Electrical industries & 3 & & 0.06 & \\
\hline Textiles and clothing industries & 3 & & 0.06 & \\
\hline
\end{tabular}


of data. According to ASE (2018), industrial sector is classified into 9 sub-sectors depending on their activity.

In fact, there are 46 listed manufacturing companies in the ASE as of December 31, 2018, which included about 322 electronic annual reports over the period 2012-2018. Specifically, this period is the suitable time to investigate the quantity and quality of CSD in corporate reports because the data during this period may become even more useful and more inclusive of sustainability practices.

\section{RESULTS AND DISCUSSION}

This section looks into the quantity and quality of CSD by sampled listed Jordanian industrial companies during 2012-2018. The GRI criteria adopted in obtaining the quantity and quality of CSD by sampled companies have been outlined in the next two subsections. Thus, the next sub-section presents the quantity of the disclosure.

\subsection{Quantity of CSD}

Figure 1 indicates that in the online reporting, all the sustainability aspects have reported a remarkable growth in the total words count in quantitative terms over the seven-year period. Furthermore, it indicates that Jordanian industrial companies made the disclosure on all aspects of sustainability for the period under review. In fact, the total words count of sustainability disclosure practices in the corporate online reporting from 2012 to 2018 is 25,882 words. This result represents the total of the collected words in the aspects of economic, environmental, and social responsibilities, as shown in Figure 1.

Despite the amount of sustainability information seeming somewhat satisfactory in the period 2012-2018, there is still modest disclosure about the GRI environmental and economic indicators. Specifically, there was a variation in the total amount of words count among social, environmental, and economic indicators. During the period 2012-2018, there was a clear growth of social indicators compared to other sustainability indicators, where it constitutes $44 \%$ of total amount of sustainability disclosure for 7 years.

About $27 \%$ and $29 \%$ of the total words of sustainability indicators were disclosed, respectively. In fact, this result is consistent with studies by Kolk (2010) and Maubane et al. (2014) who found that the companies provided more information on social and economic aspects compared to disclosure on environmental aspect. In fact, the overall total of CSD aspects in the period under review drives this paper to an examination of the quantity of disclosure aspects by sub-sectors in the Jordanian annual reports, as shown in Figure 2.

Figure 2 shows that the sector of extraction industries has reported the highest percentage of words sustainability disclosure with $25 \%$ of total words count. This result could be attributed to the sector size, which is considered one of the largest

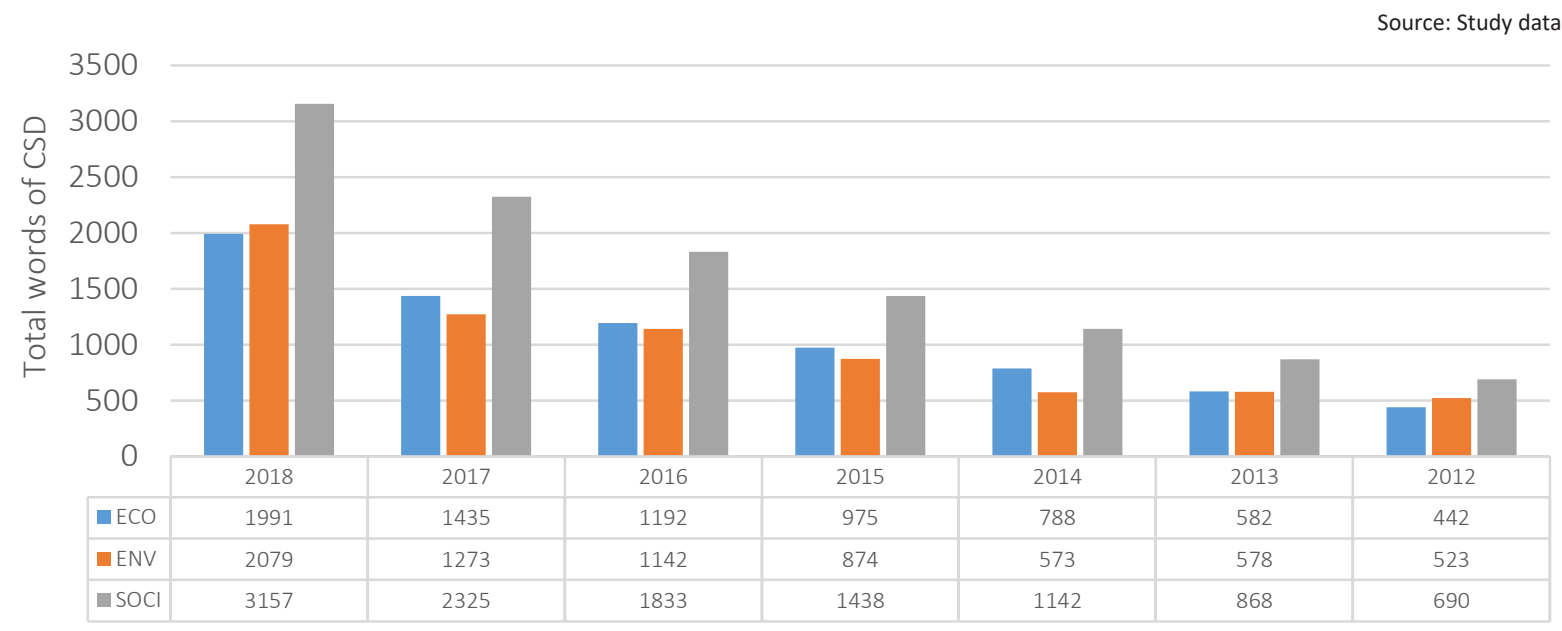

Figure 1. Total words of CSD from 2012 to 2018 


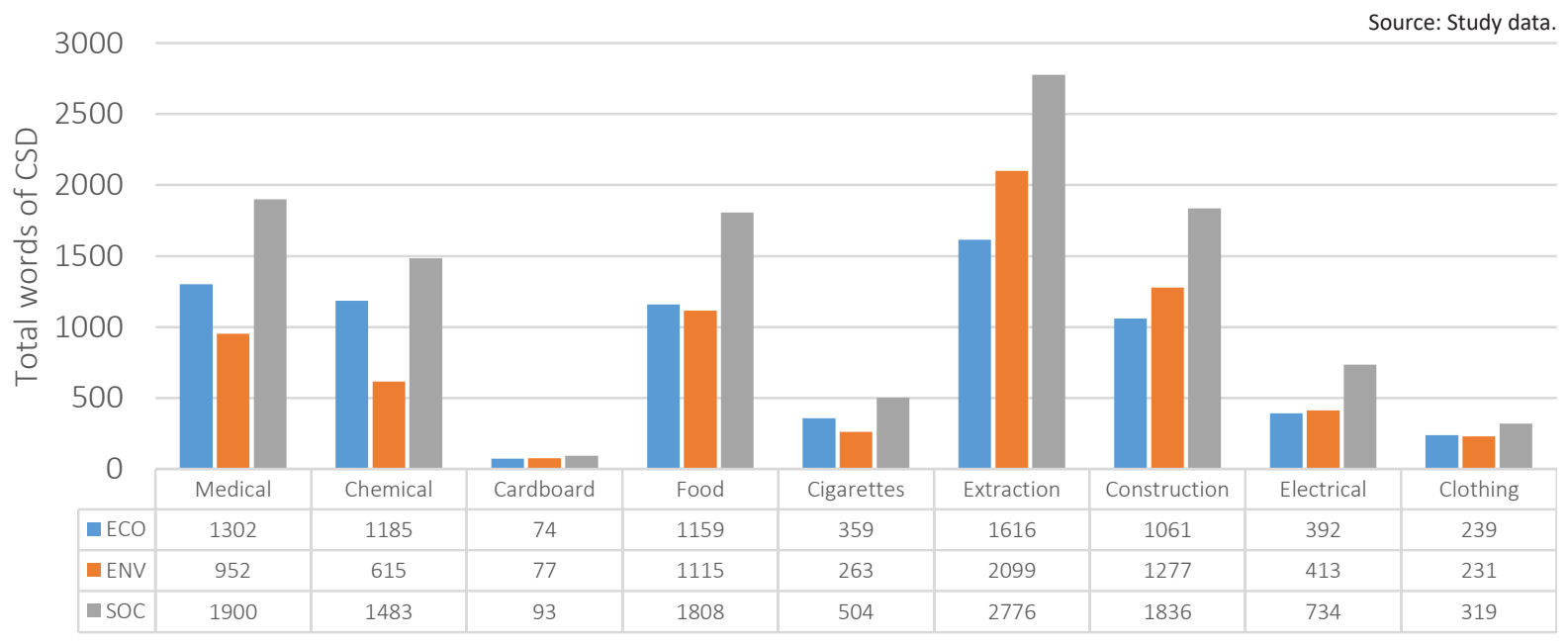

Figure 2. Total words of sustainability disclosure by sub-sectors

sub-sectors in the Jordanian economic environment. Figure 2 also indicates that the overall total of the words count of sustainability information reported by the cardboard industries sub-sector was $1 \%$. This result recorded the lowest percentage among other sub-sectors. This low amount of the sustainability information may be also attributed to sub-sector size, where it has only one listed company on the ASE.

Disclosure on sustainability information is consistent with study by Maubane et al. (2014) who found that mining and extraction sector provided more quantitative information on social aspects than the other aspects did.

After reviewing the quantitative results on CSD, it is important to look into the qualitative practices on CSD, as in the next subsection.

\subsection{Quality of CSD}

The following sub-sections are discussed in detail: the disclosure quality scores on indicators of CSD by listed Jordanian companies. Specifically, the next tables are to present the numeric results of evaluation of the quality of disclosure on all aspects of CSD. To this end, the next sub-section deals with quality of CSD in terms of (i) study period 2012-2018 and (ii) over the sub-industries.

Table 3 shows the quality of sustainability information disclosure by listed Jordanian industrial companies. It is clear that indirect economic impacts, procurement practices, product responsibility, and economic performance were the most indicators that were disclosed by the sample firms of this study. Disclosure evaluations of these sub-indicators came with a satisfactory level of quality,

Table 3. Quality of CSD indicators from 2012 to 2018

\begin{tabular}{|c|c|c|c|c|c|c|c|c|c|}
\hline \multicolumn{2}{|c|}{ Sustainability indicators } & 2018 & 2017 & 2016 & 2015 & 2014 & 2013 & 2012 & Rank \\
\hline \multirow{4}{*}{$* * *$ Eco-aspects } & Economic performance & 0.978 & 0.880 & 0.745 & 0.625 & 0.560 & 0.478 & 0.418 & $0.67 * *$ \\
\hline & Market presence & 1.087 & 0.804 & 0.576 & 0.446 & 0.435 & 0.402 & 0.348 & $0.59 *$ \\
\hline & Indirect economic impacts & 1.207 & 1.022 & 0.826 & 0.728 & 0.685 & 0.674 & 0.641 & $0.83 * *$ \\
\hline & Procurement practices & 1.000 & 0.935 & 0.696 & 0.587 & 0.543 & 0.522 & 0.587 & $0.70^{* *}$ \\
\hline \multirow{6}{*}{$* *$ Enviro-aspects } & Natural resources \& power & 0.507 & 0.389 & 0.324 & 0.296 & 0.280 & 0.276 & 0.267 & $0.33^{*}$ \\
\hline & Biodiversity & 0.125 & 0.027 & 0.011 & 0.000 & 0.000 & 0.000 & 0.000 & $0.02 *$ \\
\hline & Emissions, effluents, \& waste & 0.520 & 0.431 & 0.384 & 0.341 & 0.332 & 0.297 & 0.286 & $0.37^{*}$ \\
\hline & Services \& compliance transport & 0.565 & 0.500 & 0.413 & 0.404 & 0.352 & 0.304 & 0.322 & $0.41 *$ \\
\hline & Supplier enviro-assessment & 0.489 & 0.250 & 0.315 & 0.152 & 0.087 & 0.022 & 0.011 & $0.19 *$ \\
\hline & Enviro-grievance-mechanisms & 0.565 & 0.543 & 0.543 & 0.522 & 0.522 & 0.522 & 0.500 & $0.53^{*}$ \\
\hline \multirow{4}{*}{ *Soci-aspects } & Labor practices \& decent work & 0.622 & 0.486 & 0.361 & 0.280 & 0.234 & 0.168 & 0.111 & $0.32 *$ \\
\hline & Human rights & 0.377 & 0.301 & 0.237 & 0.187 & 0.143 & 0.116 & 0.096 & $0.21^{*}$ \\
\hline & Society responsibility & 0.433 & 0.387 & 0.308 & 0.302 & 0.257 & 0.261 & 0.239 & $0.31^{*}$ \\
\hline & Product responsibility & 0.850 & 0.804 & 0.732 & 0.679 & 0.635 & 0.592 & 0.507 & $0.69 * *$ \\
\hline
\end{tabular}

Note: $*$ Social aspects, $* *$ Environmental aspects, $* * *$ Economic aspects. 
Table 4. Quality of CSD indicators by sub-sectors

Source: Study data.

\begin{tabular}{|c|c|c|c|c|c|c|c|c|c|}
\hline Aspect & Medical & Chemical & Cardboard & Food & Cigarettes & Extraction & Construction & Electrical & Clothing \\
\hline SOC & 0.477 & 0.311 & 0.167 & 0.320 & 0.372 & 0.449 & 0.418 & 0.354 & 0.137 \\
\hline ENV & 0.467 & 0.185 & 0.176 & 0.264 & 0.265 & 0.410 & 0.400 & 0.318 & 0.183 \\
\hline ECO & 0.976 & 0.823 & 0.381 & 0.665 & 0.754 & 0.744 & 0.630 & 0.540 & 0.217 \\
\hline Total & $64 \%$ & $44 \%$ & $24 \%$ & $42 \%$ & $46 \%$ & $53 \%$ & $48 \%$ & $40 \%$ & $18 \%$ \\
\hline
\end{tabular}

but without compliance with GRI indicators. In fact, they ranked with a medium score when evaluating the quality of disclosure indicators about $83 \%, 70 \%, 69 \%$, and $67 \%$, respectively, while the remaining qualitatively indicators have been rated with a low quality level. Specifically, the quality evaluations of disclosure indicators came up with low-level, which were scored 0.00-0.68. In other words, any qualitatively indicator that scored less than 0.68 is rated as unsatisfactory. Compared to highest scores, both biodiversity and supplier envoi-assessment indicators both came at a very low-level among sustainability indicators, which scored of $2 \%$ and $19 \%$ respectively.

Overall, the results in Table 3 indicate that the evaluation on quality information of CSD that was disclosed by Jordanian industrial companies was predominantly unsatisfactory over the period of the study from 2012 to 2018. This result of unsatisfactory quality scores is consistent with Ching et al. (2013), Chiu and Wang (2015) who found the same level of unsatisfactory quality of disclosure. In line with the nature of research sample, this section also can provide us with further expla- nation on the quality information of CSD by the Jordanian industrial sub-sectors, as presented in Table 4.

Although it can be seen from Table 4 that the evaluation of overall results on the quality of disclosure on all the Jordanian industrial sub-sectors are rated as unsatisfactory, CSD is witnessing a remarkable growth towards a better level of quality in several sectors. For example, about $64 \%, 53 \%$, $48 \%, 46 \%$, and $44 \%$ in the medical, extraction, construction, cigarettes, and chemical industries, respectively. Comparing to the highest findings, clothing and cardboard industries scored the lowest percentages $18 \%$ and $24 \%$, respectively. These percentages reflect very low level in the quality of CSD in such sectors. This low level of disclosure may be due to the size of such sub-sectors, which are reported as the smallest sectors in Jordanian economic environment. This finding of unsatisfactory quality scores is consistent with studies of Chiu and Wang (2015), Maubane et al. (2014), Ching et al. (2013) who found in their studies that the companies provided little quality information on sustainability aspects.

\section{CONCLUSION}

The motive of this paper is to use the GRI index to describe the disclosure practices of listed Jordanian industrial companies. Listed Jordanian industrial companies are disclosing many aspects of sustainability performance in their online reports as legitimacy strategy. However, it was found that the compliance of sustainability information in accordance with the GRI guidelines did not reach the desired level of commitment to the majority of disclosure indicators.

This low level of quantitative and qualitative sustainability information disclosure by the Jordanian industrial companies could be explained as reflecting regression of public awareness of internal stakeholders and low level of accountability among external stakeholders about many sustainability issues. Therefore, it could be argued that there is no general thought among Jordanian society about the issue of legitimacy and corporate accountability, which could have motivated Jordanian companies to provide more sustainability information than reported.

Overall, and at the applied level, the obtained findings should motivate government commitment to the sustainable development of all Jordanian sectors by strengthening the legal frameworks that help to 
solidify the practices of corporate sustainability and report them. Furthermore, on the theoretical level, it might be considered as a direct motive to the future research to study more CSD issues in different sectors and different countries.

\section{REFERENCES}

1. Abd-Mutalib, H., Jamil, C., \& Hussin, W. (2014). The Availability, Extent \& Quality of Sustainability Reporting by Malaysian Listed Firms: Subsequent to Mandatory Disclosure. Asian Journal of Finance \& Accounting, 6(2), 239257. https://doi.org/10.5296/ajfa. v6i2.6108

2. Abu-Baker, N., \& Naser, K. (2000). Empirical Evidence on Corporate Social Disclosure (CSD) Practices in Jordan. International Journal of Commerce and Management, 10(3/4), 18-34. http://dx.doi. org/10.1108/eb047406

3. Adams, C., \& Frost, G. (2006). Accessibility \& Functionality of the Corporate Web Site: Implications for Sustainability Reporting. Business Strategy \& the Environment, 15(4), 275-87. https://doi. org/10.1002/bse.531

4. Alcaraz-Quiles, F., NavarroGalera, A., \& Ortiz-Rodriguez, D. (2015). Factors determining online sustainability reporting by local governments. International Review of Administrative Sciences, 81(1), 79-109. https:/doi. org/10.1177/0020852314541564

5. Anderson, D. (2010). Statistics for Business \& Economics (2nd ed.). Cengage Learning EMEA.

6. ASE (2018). The ASE Issued the Guidance on Sustainability Reporting. Retrieved from https:// www.ase.com.jo/en/news/ASEissued-Guidance-SustainabilityReporting

7. BCCCCEY (2013). Boston College Center for Corporate Citizenship, Value of Sustainability Reporting. Retrieved from https://www. ey.com/Publication/vwLUAssets/ EY_Value_of_Sustainability_ Reporting/\%24File/EY-Sustainability.pdf

8. Branco, M., \& Rodrigues, L. (2006). Communication of
Corporate Social Responsibility by Portuguese Banks. Corporate Communications, 11(3), 232-248. https://doi. org/10.1108/13563280610680821

9. Campbell, D., Craven, B., \& Shrives, P. (2003). Voluntary Social Reporting in Three FTSE Sectors: A Comment on Perception and Legitimacy. Accounting, Auditing \& Accountability Journal, 16(4), 558-581. https://doi. org/10.1108/09513570310492308

10. Campopiano, G., De-Massis, A., \& Cassia, L. (2012). The Relationship Between Motivations and Actions in Corporate Social responsibility an Exploratory Study. International Journal of Business and Society, 13(3), 391-425. Retrieved from https://www.researchgate. net/publication/281133640_The_ relationship_between_motivations_and_actions_in_corporate_social_responsibility_An_exploratory_study

11. Ching, H., Gerab, F., \& Toste, T. (2013). Analysis of Sustainability Reports \& Quality of Information Disclosed of Top Brazilian Companies. International Business Research, 6(10), 62-77. https://doi. org/10.5539/ibr.v6n10p62

12. Chiu, T. K., \& Wang, Y. H. (2015). Determinants of Social Disclosure Quality in Taiwan: An Application of Stakeholder Theory. Journal of Business Ethics, 129(2), 379398. Retrieved from https://link. springer.com/article/10.1007/ s10551-014-2160-5

13. Cormier, D., \& Gordon, I. (2001). An Examination of Social and Environmental Reporting Strategies. Accounting, Auditing \& Accountability Journal, 14(5), 587-617. https://doi.org/10.1108/ EUM0000000006264

14. Deegan, C., \& Rankin, M. (1996). Do Australian Companies Report Environmental News Objectively?
Accounting, Auditing \& Accountability Journal, 9(2), 50-67. https://doi. org/10.1108/09513579610116358

15. Deegan, C. (2007). Financial accounting theory (2nd ed.). Australia: McGraw-Hill.

16. Dissanayake, D., Tilt, C., \& Xydias-Lobo, M. (2016). Sustainability Reporting by Publicly Listed Companies in Sri Lanka. Journal of Cleaner Production, 129, 169-182. https://doi.org/10.1016/j. jclepro.2016.04.086

17. Dowling, J., \& Pfeffer, J. (1975). Organizational Legitimacy: Social Values \& Organizational Behavior. Pacific Sociological Review, 18(1), 122-136. https://doi. org/10.2307/1388226

18. Frost, G., Jones, S., Loftus, J., \& Laan, S. (2005). A Survey of CSR Reporting Practices of Australian Reporting Entities. Australian Accounting Review, 15(35), 89-96. https://doi. org/10.1111/j.1835-2561.2005. tb00256.x

19. Gray, R., Kouhy, R., \& Lavers, S. (1995). Corporate Social and Environmental Reporting. Accounting, Auditing \& Accountability Journal, 8(2), 47-77. https://doi. org/10.1108/09513579510146996

20. GRI (2013). Sustainability Reporting can Serve as Bridge Between Business and Sustainable Development. Retrieved from https://www. globalreporting.org/information/ news-and-press-center/Pages/ Sustainability-reporting-can-serveas-bridge-between-business-andsustainable-development-says-GRI. aspx

21. Guthrie, J., Cuganesan, S., \& Ward, L. (2008). Industry Specific Social and Environmental Reporting: The Australian Food and Beverage Industry. Accounting Forum, 32(1), 1-15. https://doi.org/10.1016/j.accfor.2007.10.001 
22. Guthrie, J., \& Parker, L. (1989). Corporate Social Reporting: A Rebuttal of Legitimacy Theory. Accounting \& Business Research, 19(76), 343-353. https://doi.org/10. 1080/00014788.1989.9728863

23. Hahn, R., \& Kühnen, M. (2013). Determinants of sustainability reporting: a review of results, trends, theory, and opportunities in an expanding field of research. Journal of Cleaner Production, 59, 5-21. https://doi.org/10.1016/j. jclepro.2013.07.005

24. Herzig, C., \& Godemann, J. (2010). Internet-Supported Sustainability Reporting: Developments in Germany. Management Research Review, 33(11), 1064-1082. http://dx.doi. org/10.1108/01409171011085903

25. Huang, T., \& Wang, A. (2010). Sustainability Reports in China: Content Analysis (pp. 154-158). International Conference on Future Information Technology \& Management Engineering. Cape Town, Curran Associates. https://doi. org/10.1109/FITME.2010.5654711

26. Kolk, A. (2010). Trajectories of Sustainability Reporting by MNCs. Journal of World Business, 45(4), 367-374. https://doi.org/10.1016/j. jwb.2009.08.001
27. Maubane, P., Prinsloo, A., \& Van Rooyen, N. (2014). Sustainability Reporting Patterns of Companies Listed on the Johannesburg Securities Exchange. Public Relations Review, 40(2), 153-160. https://doi. org/10.1016/j.pubrev.2014.02.014

28. Morhardt, E. (2010). Corporate Social Responsibility \& Sustainability Reporting on the Internet. Business Strategy \& the Environment, 19(7), 436-452. https://doi.org/10.1002/ bse. 657

29. O’Dwyer, B., Unerman, J., \& Bradley, J. (2005). Perceptions on the Emergence \& Future Development of Corporate Social Disclosure in Ireland. Accounting, Auditing \& Accountability Journal, 18(1), 14-43. https://doi. org/10.1108/09513570510584647

30. Rezaee, Z. (2017). Corporate Sustainability: Theoretical and Integrated Strategic Imperative and Pragmatic Approach. Journal of Business Inquiry, 16(1), 60-87. Retrieved from https://papers.ssrn. com/sol3/papers.cfm?abstract_ id $=3148705$

31. Roberts, D., \& Koeplin, J. (2007). Sustainability Reporting Practices in Portugal: Greenwashing or Triple Bottom line? International Business \& Economics Research Journal, 6(9),
29-40. https://doi.org/10.19030/iber. v6i9.3403

32. Samy, M., Odemilin, G., \& Bampton, R. (2010). Corporate Social Responsibility: a Strategy for Sustainable Business Success. An Analysis of 20 Selected British Companies. Corporate Governance: The International Journal of Business In Society, 10(2), 203-217. http://dx.doi. org/10.1108/14720701011035710

33. Sobhani, F., Amran, A., \& Zauniddin, Y. (2012). Sustainability Disclosure in Annual Reports \& Websites: A Study of the Banking Industry in Bangladesh. Journal of Cleaner Production, 23(1), 75-85. https://doi. org/10.1016/j.jclepro.2011.09.023

34. Suchman, M. (1995). Managing Legitimacy: Strategic \& Institutional Approaches. Academy of Management Review, 20(3), 571-610. https://doi.org/10.2307/258788

35. Tyler, T. (2006). Psychological Perspectives on Legitimacy and Legitimation. Annual Review of Psychology, 57, 375-400. https:// doi.org/10.1146/annurev. psych.57.102904.190038

36. Yaftian, A. (2011). An Analysis of CSR Contents in Annual Reports of Listed Companies in Iran (Ph.D thesis). Deakin University, Melbourne, Australia. 